Article

\title{
Application of Virtual Reality for Learning the Material Properties of Shape Memory Alloys
}

\author{
Wernhuar Tarng ${ }^{1, *(\mathbb{D}}$, Chia-Jung Chen ${ }^{2}$, Chi-Young Lee ${ }^{1}$, Chih-Ming Lin $^{1}$ and Yu-Jun Lin ${ }^{1}$ \\ 1 National Tsing Hua University, Hsinchu 30013, Taiwan; cylee@mx.nthu.edu.tw (C.-Y.L.); \\ cmlin@mail.nd.nthu.edu.tw (C.-M.L.); jwovj735@gmail.com (Y.-J.L.) \\ 2 National Hsinchu University of Education, Hsinchu 30013, Taiwan; tracy083535@gmail.com \\ * Correspondence: wtarng@mail.nd.nthu.edu.tw; Tel.: +886-3-5715131
}

Received: 11 January 2019; Accepted: 7 February 2019; Published: 10 February 2019

check for updates

\begin{abstract}
A shape memory alloy (SMA) is an alloy which can eliminate deformation at lower temperatures and restore its original shape upon heating. SMAs have been receiving considerable attention in the research field of materials science, and their applications include robotics, automotive, aerospace, and biomedical industries. Observing the SMA's shaping and restoration processes is important for understanding its working principles and applications. However, the transformation of its crystal structure with temperature can only be seen using special equipment, such as a transmission electron microscope (TEM), which is an expensive apparatus and the operation requires professional skills. In this study, a teaching module is designed using virtual reality (VR) technology and research results of an SMA to show its shape memory properties, shaping and restoration processes, as well as the real-life applications in an immersive and interactive way. A teaching experiment has been conducted to analyze students' learning effectiveness using the teaching module (the experimental group) compared with that of using real SMA materials as the teaching aids (the control group). Two classes of students in the Department of Materials Science (one as the experimental group and the other as the control group) were selected as the samples by convenience sampling from a university in North Taiwan. The experimental group contained 52 students and the control group contained 70 students. A nonequivalent pretest-posttest design was adopted to explore whether the two groups had a significant difference in learning effectiveness. The experimental results reveal that the teaching module can improve the learning effectiveness significantly $(p=0.001)$, and the questionnaire results also show that a majority of the students had positive attitudes about the teaching module. They believed that it could increase their learning motivation and help them understand the properties and applications of the SMA.
\end{abstract}

Keywords: virtual reality (VR); shape memory alloy (SMA); transmission electron microscope (TEM); austenite; martensite

\section{Introduction}

Shape-memory alloy (SMA), also known as memory metal or smart metal, is an alloy which can fully eliminate the deformation at a lower temperature and restore its original shape when heated. In addition to the shape memory property, SMAs are lightweight and resistant to most chemicals. Some SMAs have the features of super elasticity, damping capacity, and biological compatibility, so they are widely applied in aviation, robotics, and biomedical industries. The SMA products in real life include: self-adjusting dental braces, optical frames, vascular stents, and so on. SMAs can effectively save the cost of repeated shape adjustment and extend the lifetime of a product.

The shape memory property was first discovered by Chang and Read [1] in Au-Cd alloy at the University of Illinois in 1951. A similar property had also been found by Buehler, Gilfrich, and Wiley [2] 
in Ni-Ti alloy at the U.S. Naval Ordnance Laboratory in 1963. Since then, SMAs began to receive the attention of researchers in materials science and related industries. The applications of SMAs grew extensively by the successive finding of the shape memory properties in other alloys, such as $\mathrm{Cu}-\mathrm{Al}-\mathrm{Ni}$, $\mathrm{Fe}-\mathrm{Mn}-\mathrm{Si}$, and $\mathrm{Cu}-\mathrm{Zn}-\mathrm{Al}$ [3-5]. More recent applications of SMAs include space antennas, military aircrafts, civil engineering, and medical treatment [6-9].

The transition temperature for the transformation of an SMA's material structure can vary with its crystal size, applied stress, thermal cycling times, and other factors [10], among which the proportion of the alloy ingredients has the major influence. Therefore, the applications of the SMA can be determined by controlling the proportion of its ingredients. In addition, the smelting during the manufacture of an SMA can be affected by its constituent elements. Some alloys can be directly smelted in the air, but others may react with oxygen to affect their properties. Taking the $\mathrm{Ni}$-Ti alloy as an example, it must be hot rolled at $800-900{ }^{\circ} \mathrm{C}$ by high-frequency vacuum induction melting, then forged at $700-850{ }^{\circ} \mathrm{C}$ and finally crushed into the sheet or thread shape by processing in a cold room. This process can cause hardening, which is not favorable for many applications. Thus, an annealing process is often required to eliminate the hardening effect.

A simplified SMA manufacturing process proposed by Markopoulos, Pressas, and Manolakos [11] is shown in Figure 1. To create the shape memory property, the SMA is fixed to the designated shape after the annealing process, then heated to about $400-500{ }^{\circ} \mathrm{C}$ while maintaining the shape and finally cooled down. If there is any deformation caused by external force at room temperature, the SMA will return to the memorized shape by simply heating it to the transition temperature.

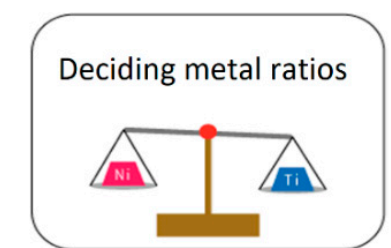

(a)

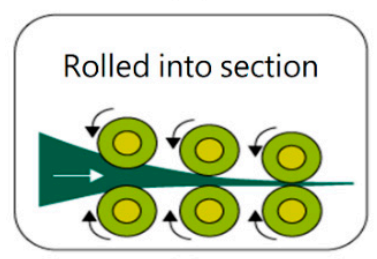

(d)

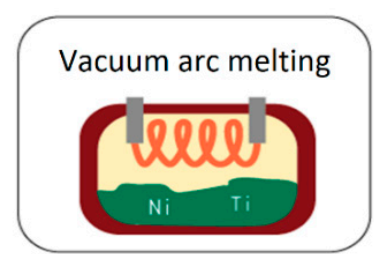

(b)

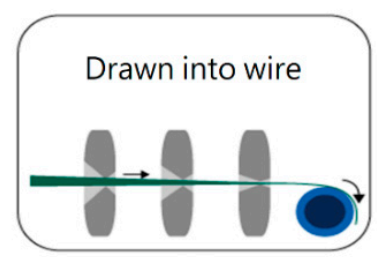

(e)

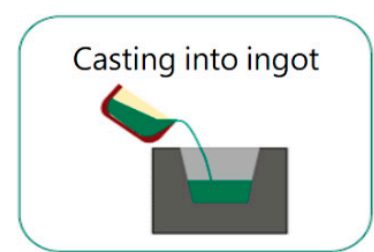

(c)

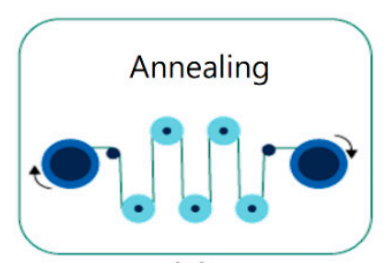

(f)

Figure 1. A simplified manufacturing process of the SMA.

SMAs are an important research field in materials science and engineering. Observing the shaping and restoration processes of an SMA is essential for understanding its basic properties and applications. Supported by the Ministry of Science and Technology (MOST), Taiwan, the objective of this study is to develop a teaching module for the students in the Department of Materials Science and Engineering of a university in North Taiwan to understand the material properties of SMA, conduct the SMA shaping experiment, and become familiar with its real-life applications. The teaching module can also be applied to support the materials science curriculum of other universities in Taiwan. However, it is time-consuming and costly to conduct real shaping experiments using SMA materials, and the waste materials must be disposed of properly to avoid environmental pollution. Additionally, the transformation of crystal structures must be observed using special equipment, such as the transmission electron microscope (TEM) [12] (Figure 2), which is an expensive apparatus and only a few researchers can use it to conduct experiments. Even if the school laboratory can afford to buy one, it is not easy for students to operate it correctly due to unfamiliarity with the operational procedures and the lack of theoretical or practical foundation. All these factors cause difficulty in understanding the SMA's crystal structures and material properties. 

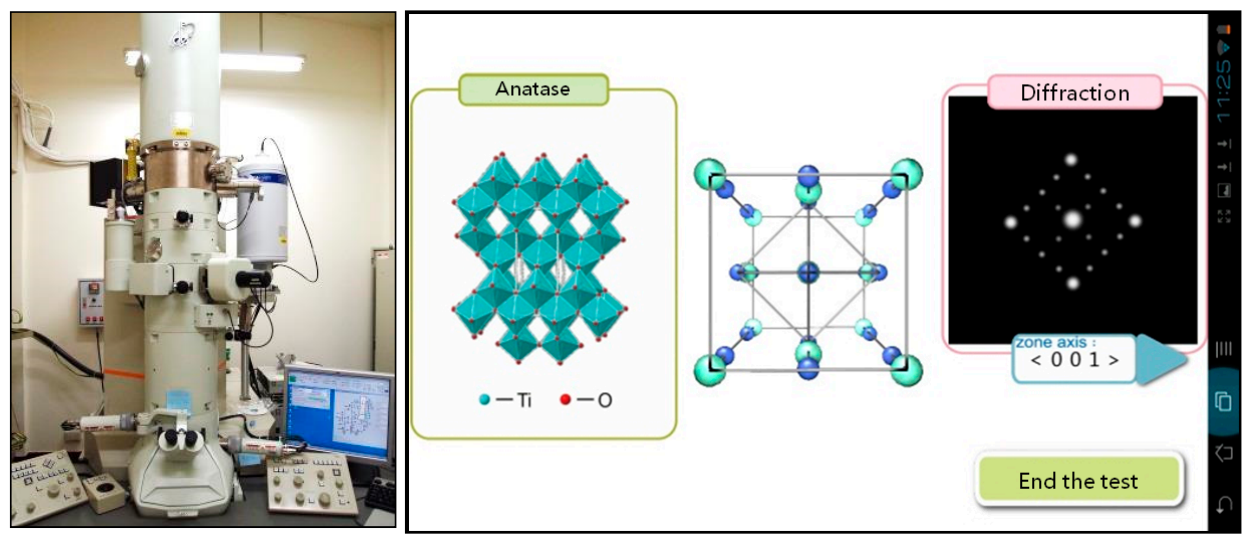

Figure 2. Using the TEM to observe a material's crystal structure.

Virtual reality (VR) is a computer-generated virtual environment to simulate the realistic or imagined world, where the 3D visual effect and interaction can be achieved by wearing a head-mounted display and button-operated handsets. It can also be called immersive multimedia because one can see and hear just like in the real situation and interact with others in the virtual world as if seeing each other face to face [13]. A virtual environment can satisfy the major requirements in the real experiments and training processes at a lower cost but without danger. VR is highly realistic and interactive, so it is suitable for applications in science and engineering education [14-16] to enhance the learning interest and motivation of students.

VR has been applied in science education to help students understand microscopic phenomena not easy to observe with the naked eye [17-19]. In addition, VR can simulate the real-world situations by 3D animation, so it is suitable for presenting abstract concepts and experimental processes to enhance immersion and cognition and increase students' engagement in learning activities [20-22]. Tarng, Hsie, Lin, and Lee [23] developed a virtual laboratory for synthesizing and analyzing nanogold particles using the virtual reality technology. A teaching experiment was conducted and the results showed that it can enhance students' learning effectiveness and motivation. de Jong, Linn, and Zacharia [24] reviewed a selection of the literature to compare the value of physical and virtual investigations and they offered recommendations for combining both approaches to strengthen science learning. Wang and Tseng [25] compared the effectiveness of physical, virtual, and virtual-physical manipulatives on third-grade students' science achievement and conceptual understanding of evaporation and condensation. Their results revealed that using virtual preceding physical manipulatives and virtual manipulatives alone can enhance students' knowledge about evaporation and condensation better than using physical laboratory activities alone. Some studies highlight that the technology itself does not improve learning outcomes, but rather reflective thinking or learners' attitudes enable improvement to learning objectives [26,27].

In this study, a teaching module is designed using the VR technology and the research results of SMAs for learning their properties, shaping, and restoration processes, as well as real-life applications (e.g., heat-driven motors and vascular stents) in an interactive and immersive way. The teaching module can be installed on mobile or head-mounted devices, enabling students to perform the virtual experiment of the SMA shaping and restoration. It can enhance the understanding of basic concepts through interactive operation and observation of structural changes with temperatures.

A teaching experiment has been conducted to analyze students' learning effectiveness and attitudes after using the teaching module. The results can also be used for improving the system in the future. The rest of this paper is organized as follows: Section 2 introduces the SMA properties and applications. Section 3 describes the development and operation of the teaching module. Section 4 reports the analytical results of the teaching experiment. Section 5 provides the conclusions. 


\section{SMA Properties and Applications}

Pure metals contain the same kind of atoms which are closely stacked, while alloys are composed of different metal atoms and they may be metal elements in a solid solution with a single phase or a mixture of two or more metallic solutions with multiple phases. Most shape memory alloys have two distinct phases, i.e., martensite and austenite. The former exists at lower temperatures, and the latter exists at higher temperatures [28]. When pure metals are deformed exceeding the elastic range by an external force, they cannot recover the original shapes by heating. In contrast, when the SMA is in the martensite phase and plastically deformed within the limited extent, it can be transformed into the austenite phase by heating to the transition temperature, where the SMA will restore its original shape (Figure 3). If the temperature goes below the normal temperature again, the SMA will still remain the same shape. The shape memory property can be applied to develop a variety of intelligent products. Therefore, SMAs belong to the area of intelligent materials.

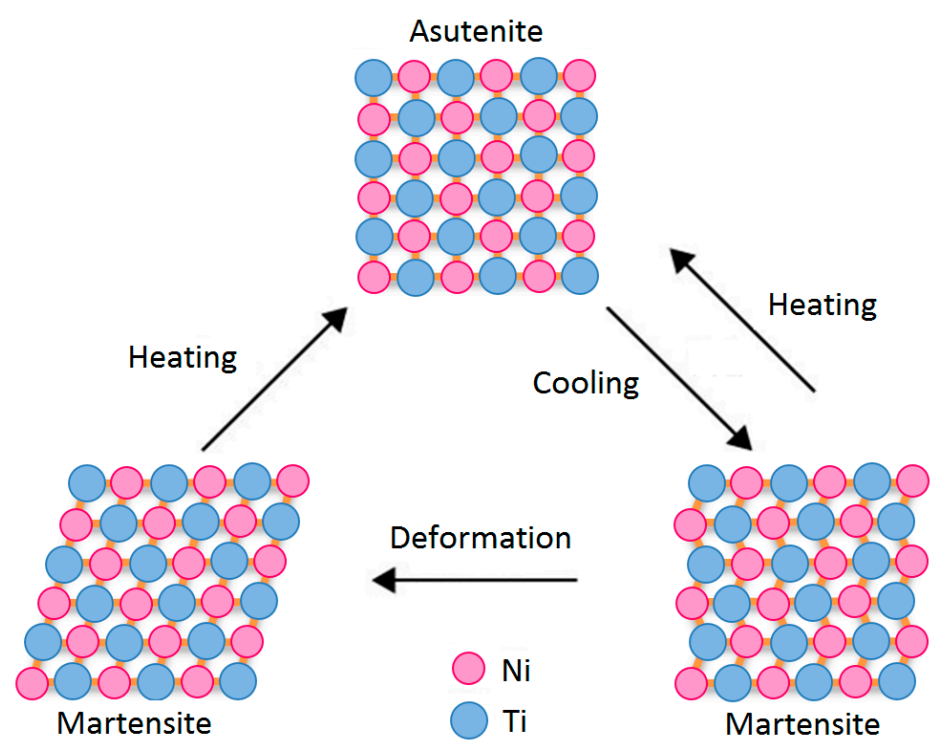

Figure 3. Transformation between the martensite and the austenite phases.

$\mathrm{Ni}$-Ti alloy is the most important and widely used SMA because of its excellent performance in shape recovery, durability, and corrosion resistance. Other attractive properties include high mechanical strength, super elasticity, biological compatibility, and stable transition temperature, providing it with a high potential for engineering and medical applications. As a result, the Ni-Ti alloy is suitable for such industries as aviation, robotics and medical treatment. However, the Ni element, a toxic metal, may affect human health and increase the risk of cancer, so it is only used in temporary appliances, such as dental braces and vascular stents.

The Ni-Ti alloy is composed of about $50 \% \mathrm{Ni}$ and $50 \% \mathrm{Ti}$, and the proportion can be adjusted according to the requirements of different applications, such as the range of transition temperatures and mechanical properties. In general, the transition temperature is lower if the content of $\mathrm{Ni}$ is higher [29]. For example, the transition temperature of the alloy with $50 \% \mathrm{Ni}$ and $50 \% \mathrm{Ti}$ is $40{ }^{\circ} \mathrm{C}$, and the alloy with $55 \% \mathrm{Ni}$ and $45 \% \mathrm{Ti}$ has shape memory capability at room temperature. If the content of $\mathrm{Ni}$ is lower than Ti, the alloy's transition temperature can reach $120^{\circ} \mathrm{C}$. Basically, the SMA shape memory effects can be divided into the following three types [30] (Figure 4):

- One-way shape memory effect

When the SMA is in the martensite phase, it can be deformed and will remain this shape until its temperature is raised above the transition temperature. Upon heating, the SMA transforms into the austenite phase and restores its original shape. The SMA will remain in this shape after cooling until deformed again. 
- Two-way shape memory effect

When the SMA is deformed with/without an external force and heated past the transition temperature, the SMA will enter the austenite phase and return to the original shape. When the temperature goes below the transition temperature, the SMA will automatically return to the memorized shape in the martensite phase. This is called the intrinsic two-way effect.

- $\quad$ All-round shape memory effect

When there is more Ni in the Ni-Ti alloy, the SMA will have an abnormal memory effect similar to the two-way shape memory effect, but its deformation is more obvious and intense. Therefore, the SMA will automatically shrink when its temperature goes below the transition temperature. When the temperature is lower, it will change to the reverse direction of the deformation. The SMA will restore the memorized shape if the temperature goes above the transition temperature of the austenite phase again.

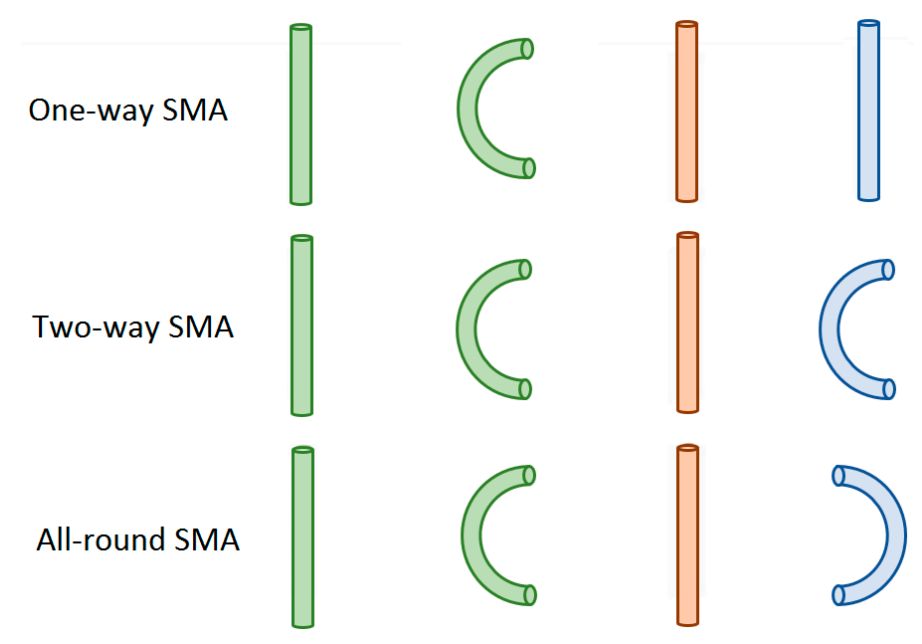

Figure 4. Different SMA shape memory effects.

In the automotive industry, SMAs can be applied in actuators, such as pneumatic, hydraulic, and motor-based systems, because of its solid-state and lightweight properties [31]. In addition, its heat conduction and shape memory properties can be used to drive a heat engine to save electric power. For medical applications, the transition temperature can be set to the body temperature if the SMA is used for the production of medical devices [32]. For example, it can be used to design fixation devices in orthopedic surgery or dental braces in orthodontics treatment to exert constant forces on teeth [33]. There are some other real-life applications of the SMA, which include:

- Vascular filter

When implanted into the vein vascular, it will gradually return to the net shape to prevent the sludged blood from flowing to the heart and the lung. It is effective for capturing and breaking apart particles in the blood.

- Vascular stent

The vascular stent is stretched to become a thin piece for inserting into the blood vessel. After the implant surgery, the blood will flow through the vascular stent and increase the temperature to restore the original shape. It is used for treating the vascular sclerosis and angiemphraxis. 
- Bone lamella

The bone lamella is used in osteosynthesis to fix two pieces of broken bones, where the pressure generated by the shape memory effect can force the broken bones to heal faster.

- Fire alarm

At room temperature, the SMA connector is bent and has no contact with the power. When a fire occurs and the temperature rises, the SMA connector will stretch automatically and touch the power to send out the alarm signal.

\section{- $\quad$ SMA-spring motor}

The length of SMA spring can change with the repeated heating and cooling process caused by the electric power to drive the motor and generate kinetic energy.

\section{System Design and Operation}

The learning contents of the teaching module are developed based on the research results of materials science and the SMA products on the market. The VR technology is used to design a virtual experiment for students to experience the shaping process and observe the change of SMA crystal structures with temperatures through interactive operation. The teaching module is an application program designed using Unity3D as the system development tool (Figure 5). Unity3D is a cross-platform game engine developed by Unity Technologies (San Francisco, CA, USA). The engine can be used to create both 3D/2D games and simulations for many platforms. The 3D objects and virtual scenes of the shaping experiment and the SMA applications are created by 3DS Max, and then exported to Unity3D to set up the interactive user interface with the programming languages of JavaScript and C\#. 3DS Max (2018, Autodesk, Inc., San Rafael, CA, USA) is a professional 3D computer graphics tool for 3D animation, modeling, games and images. It has a flexible plugin architecture and can be used on the Microsoft Windows platform. Different behaviors for the same object can be set up during the script design to meet the requirements for different situations, e.g., the change of SMA shapes with temperatures. When the project is completed, it is converted into the installation file for execution on mobile or head-mounted devices for students to conduct the virtual experiment.

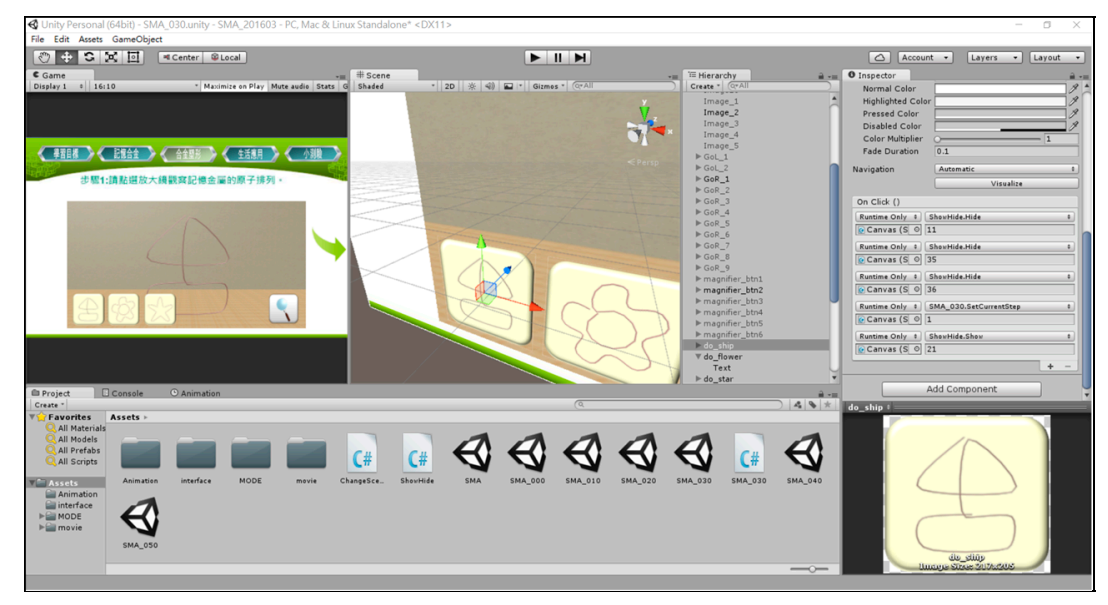

Figure 5. Using Unity3D to design the user interface in the virtual experiment.

The development of the teaching module includes three main parts (Figure 6). The first part is the creation of 3D models for the objects in the virtual experiment; the second part is setting up the properties of the objects; the third part is designing the interactive interface for students to conduct the virtual experiment. To enable easy cognition of the SMA principles and applications, the teaching 
module contains three interactive mechanisms: (1) touchscreen (or handset) control, (2) camera control, and (3) interactive user interface to support different learning activities: (4) SMA learning contents, (5) SMA shaping and manufacture, (6) real-life applications, and (7) online test. The application programming interface (API) in Unity3D as well as the C\# programming language were used to develop the user interface for conducting the SMA shaping experiment and observing the change of its crystal structure during the phase transformation. When the user starts the application program, the initial screen will show up first. The user can enter the system by clicking the start button to conduct the learning activities as listed above.

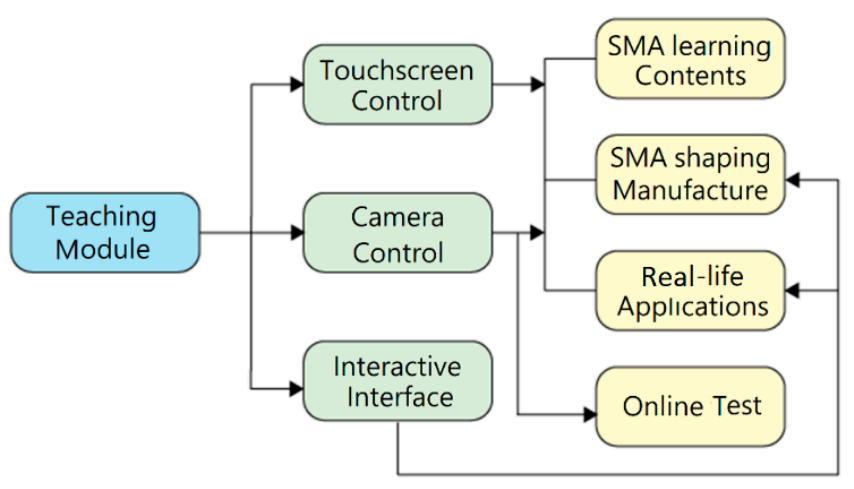

Figure 6. System architecture of the SMA teaching module.

\subsection{Learning Objectives}

The teaching module developed in this study is focused on learning the SMA material properties, principles, shaping process and real-life applications. It is designed as an application program using the VR technology for execution on mobile or head-mounted devices (Figure 7). The major purpose is to enhance the learning effectiveness and motivation and help students understand the basic concepts of SMAs through interactive operation and observation. The learning objectives of the teaching module include: (1) understanding the material properties of SMAs, (2) conducting the SMA shaping experiment, and (3) becoming familiar with the real-life applications of SMAs.
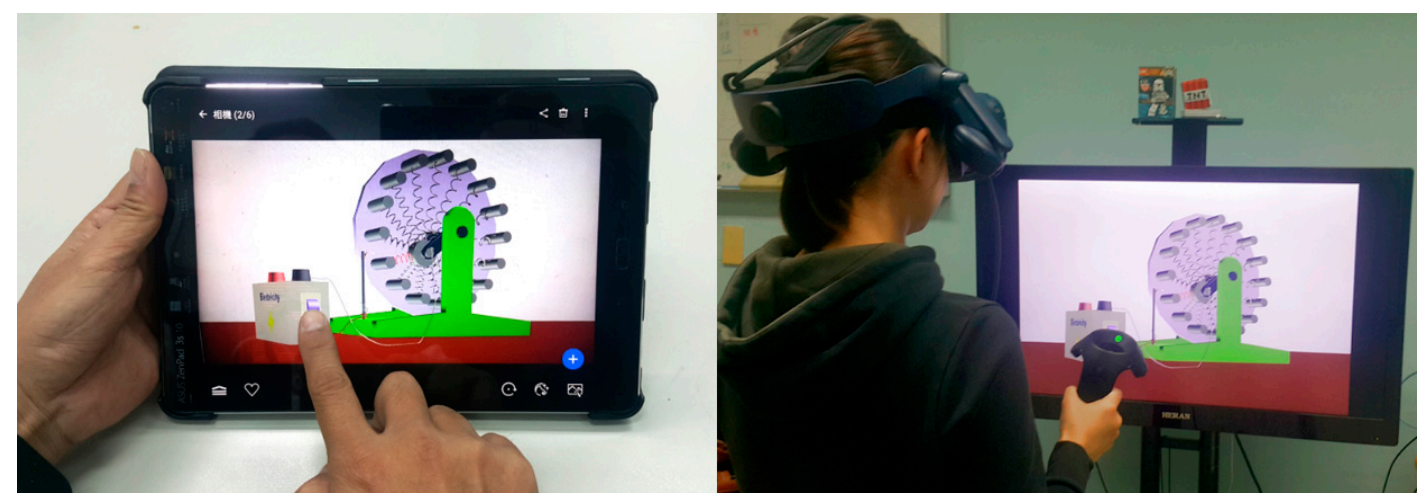

Figure 7. Conducting the virtual experiment using a mobile or head-mounted device.

\subsection{Designing 3D Models}

The 3D objects and virtual scenes of the virtual experiment are developed using 3DS Max (Figure 8). The textures are drawn with the image processing software PhotoImpact (2008, Ulead Systems, Inc., Taipei, Taiwan) and pasted onto the 3D models by adjusting the luminance according to the environmental lights to make them look like real objects. After that, the 3D models (in FBX format) are exported to Unity3D, where the API and C\# programming language are used to 
design the user interface according to the script describing the operating procedure of the shaping experiment and the SMA applications.

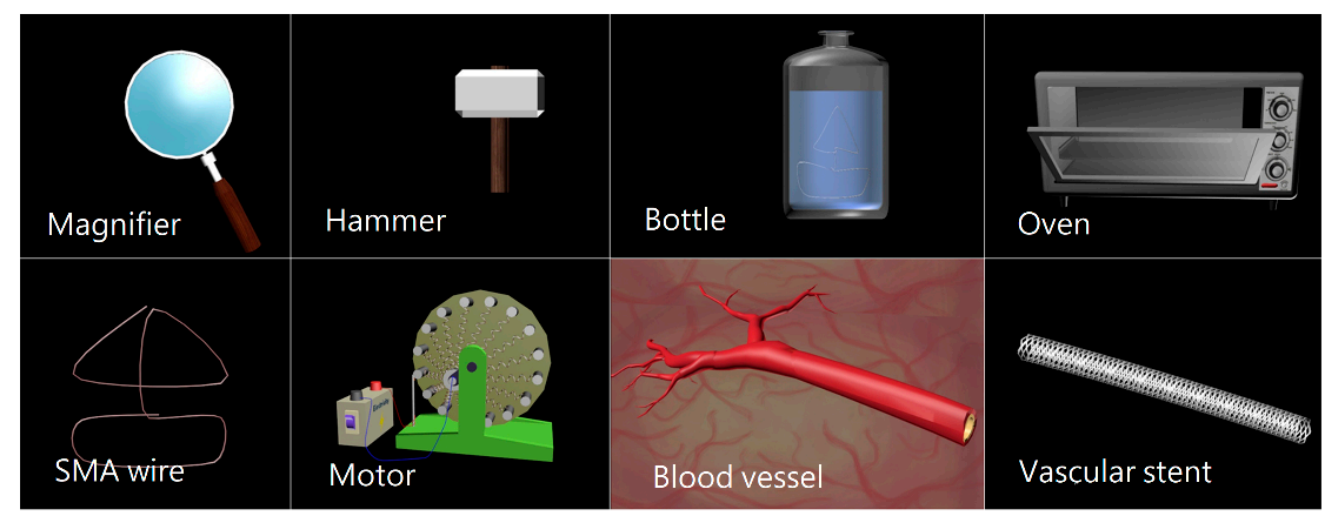

Figure 8. Using 3DS Max to design the 3D objects in the virtual experiment.

\subsection{System Architecture}

The teaching module is developed for execution on mobile and head-mounted devices, and its operating flowchart can be seen in Figure 9. After starting the system, the user can be guided by audio direction to go through each step for learning the material properties and applications of SMA. The learning objectives can be shown by clicking the leftmost button above the screen, followed by the introduction to SMA, including the learning contents of manufacture, material properties and shape memory effects. The user can conduct the virtual experiment of SMA shaping by designing a ship in a bottle using the SMA wire, and then learn about the real-life applications of the SMA, including the vascular stents and the heat-driven motor. After completing all learning activities, an online test with 10 questions has to be taken to evaluate the user's learning achievement.

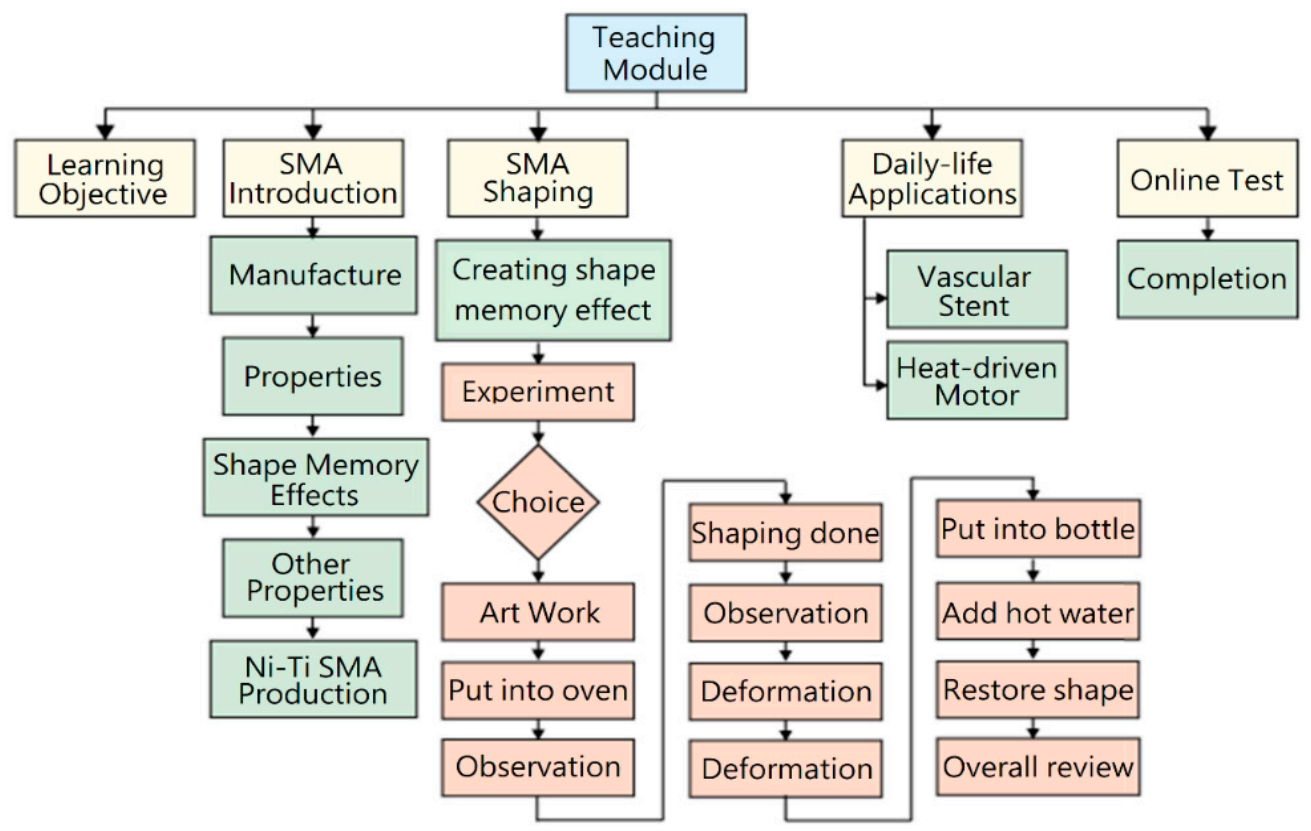

Figure 9. Operating flowchart of the SMA teaching module.

\subsection{Initial Screen}

After starting the program, the teaching module will first display the main screen, where the user can enter the system to perform the learning activities by clicking the button (Figure 10). 


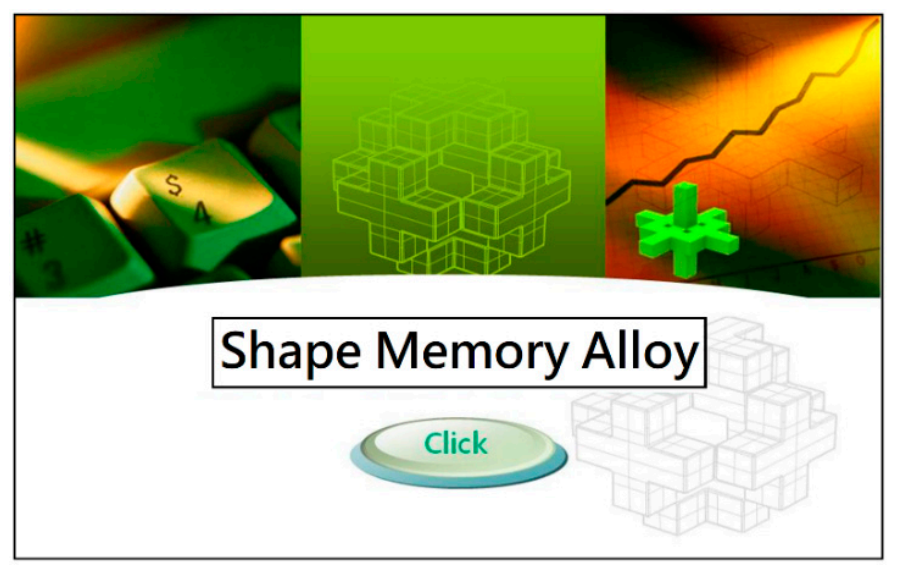

Figure 10. Initial screen of the SMA teaching module.

\subsection{Introduction to $S M A$}

The user can learn the SMA properties and shape memory effects by entering the learning unit 'Introduction to SMA', which includes the definition of SMA and its properties, shape memory effects, crystal structures, and manufacture of the Ni-Ti SMA (Figure 11).

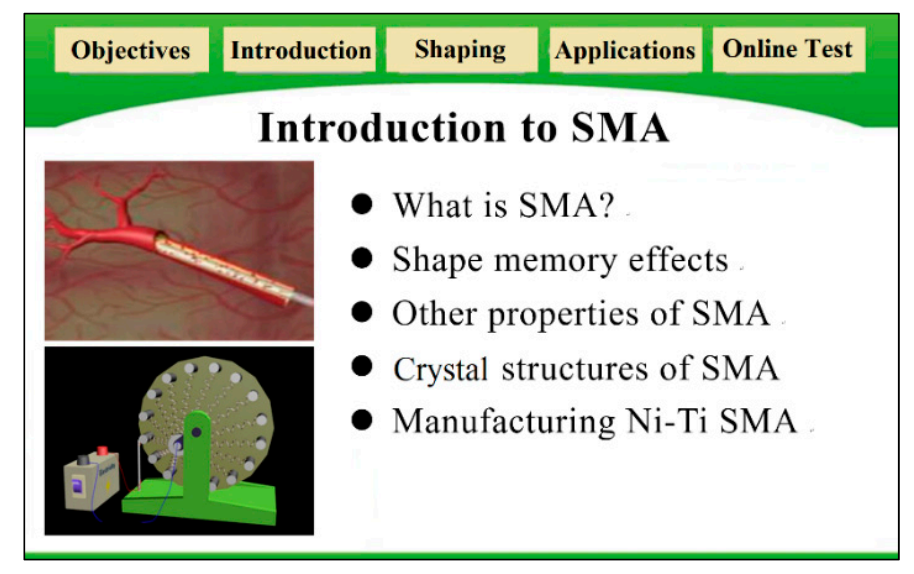

Figure 11. Learning the basic concepts of SMA.

\subsection{SMA Shaping Experiment}

The user can understand the SMA's shape memory properties by following the experimental procedure to observe the change of it crystal structure with temperatures (Figure 12). The purpose of this experiment is to design a ship in a bottle with the SMA wire.

The user has to fold a piece of SMA wire into the shape of a ship and put it in the oven at $500{ }^{\circ} \mathrm{C}$ for five hours. After that, the ship is taken out of the oven and cooled down to room temperature. To check if the SMA wire has memorized the shape of a ship, the user hits the ship with a hammer and deforms it into a thinner piece of SMA wire such that it can be inserted into a narrow-mouth glass bottle. Then, the user pours hot water into the bottle to see if the deformed ship can recover its original shape. During the experiment, the user can observe the change of the SMA's crystal structure between the austenite and the martensite phases using the magnifier, a symbol of the observation tool for viewing the SMA crystal structure. Finally, the phase transformation in each step of the experiment is shown as a review for the whole shaping and restoration process. 

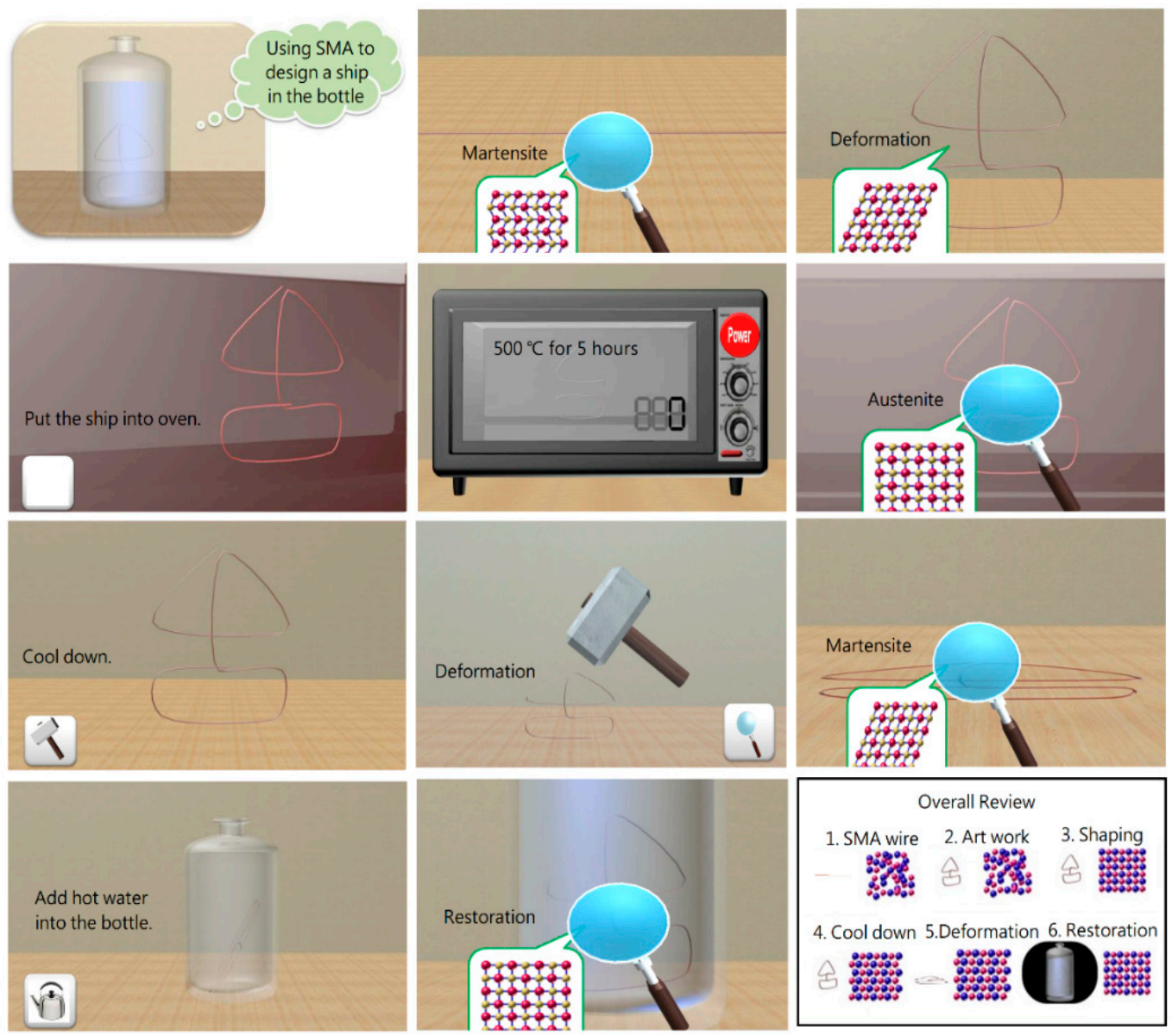

Figure 12. Virtual experiment: designing a ship in a bottle using the SMA wire.

\subsection{SMA Applications}

The learning unit 'SMA Applications' introduces two examples of real-life applications, i.e., the heat-driven motor and the vascular stent. The user can observe how the SMA material changes its shape and crystal structure with temperatures to understand the working principles. In the first example, the user can turn on the power supply to see the motor driven by the SMA spring, which is heated by the electric power and shrink to generate the tensile force (Figure 13). After the rotation by a small degree, the heated spring is disconnected from the power supply such that it cools down and becomes loose. However, the succeeding SMA spring is connected with the power supply; it is heated and shrinks to generate the tensile force for the motor to continue rotation.

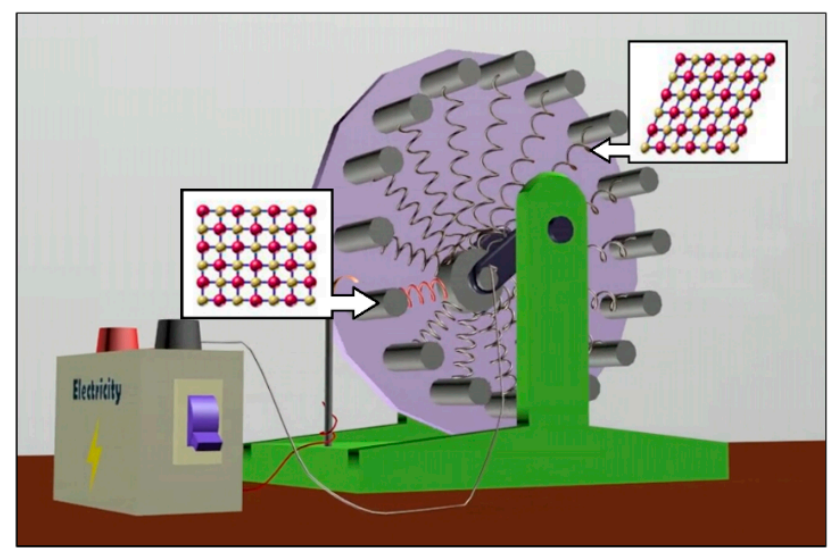

Figure 13. The heat-driven motor using SMA springs. 
The second example shows the application of SMA in vascular stents for dilating the blood vessel. Before the vascular stent is implanted into the blood vessel, the blood is stopped by clamps to keep the vascular at a lower temperature. The vascular stent is stretched to become a very thin piece for inserting into the blood vessel. After that, the clamps are removed and the blood is allowed to flow through the blood vessel. The blood temperature will trigger the phase transition and enable the vascular stent to restore its original shape for dilating the blood vessel (Figure 14).

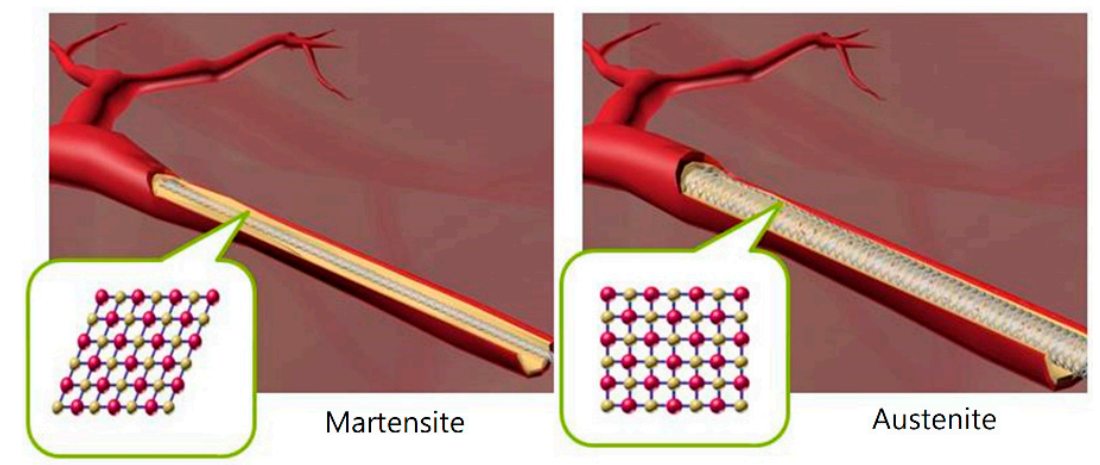

Figure 14. The SMA vascular stent for dilating the blood vessel.

\subsection{Online Test}

After the completion of all learning activities, the teaching module will require the user to assess the learning achievement by taking the online test. There are 10 multiple-choice questions designed based on the contents of the teaching module and they were reviewed by the SMA experts to ensure their correctness. After clicking the button 'Online Test', the system will show the test question one after another and the user can choose the correct answer accordingly (Figure 15).
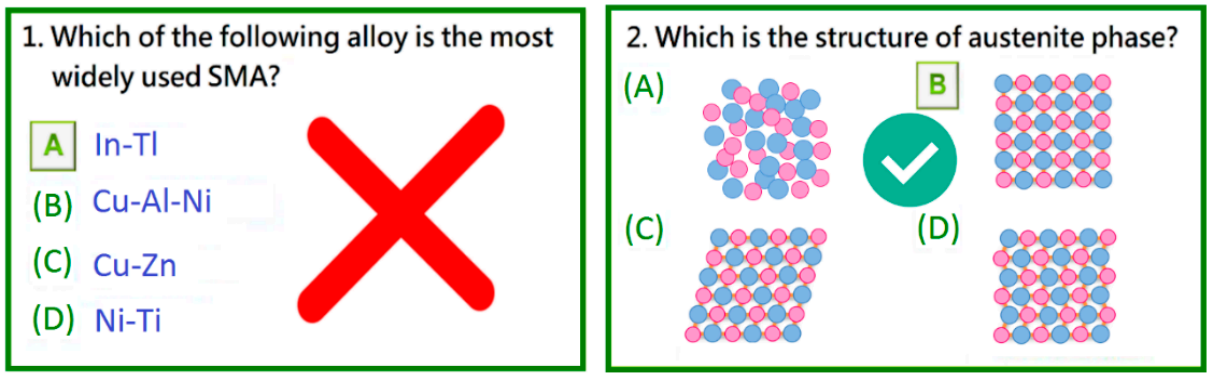

Figure 15. System response after answering the questions.

In Figure 15, the first question asks "Which of the following alloy is the most widely used SMA?" The user can select any answers from the list of alloys. If the user's selection is (D): "Ni-Ti", the screen will show a correct mark and go to the next question; if a wrong answer has been selected (A, B, or C), the system will display the incorrect mark and request the user to answer again. Similarly, the second question asks "Which is the structure of austenite phase?" The system will reply "You are right." and show a correct mark if the user chooses (B) or show the incorrect mark and request the user to answer again if the he or she selects other answers.

\section{Teaching Experiment}

A teaching experiment has been conducted to measure the performance of the teaching module in learning the SMA's properties and applications. A questionnaire survey has been performed to explore students' attitudes after using the teaching module. Two classes of students were selected as the experimental samples from the Department of Materials Science of a university in North Taiwan. The control group contained 70 students and the experimental group contained 52 students due to 
convenience sampling. The former was given an SMA lecture and used the SMA wire as the teaching aids to conduct the real shaping experiment. The latter conducted the virtual experiment using the SMA teaching module after taking the same lecture.

A nonequivalent pretest-posttest design was adopted in the teaching experiment to explore whether the two groups had a significant difference in learning effectiveness. The students in both groups took a pretest to assess their SMA knowledge before the teaching activities, and then the posttest was taken after the teaching activities while the experimental group also needed to fill out a questionnaire to measure their attitudes after using the teaching module. The questionnaire results can be referred for improving the teaching module in the future. Figure 16 shows the flowchart of the teaching experiment, and its variables of are listed in Table 1.

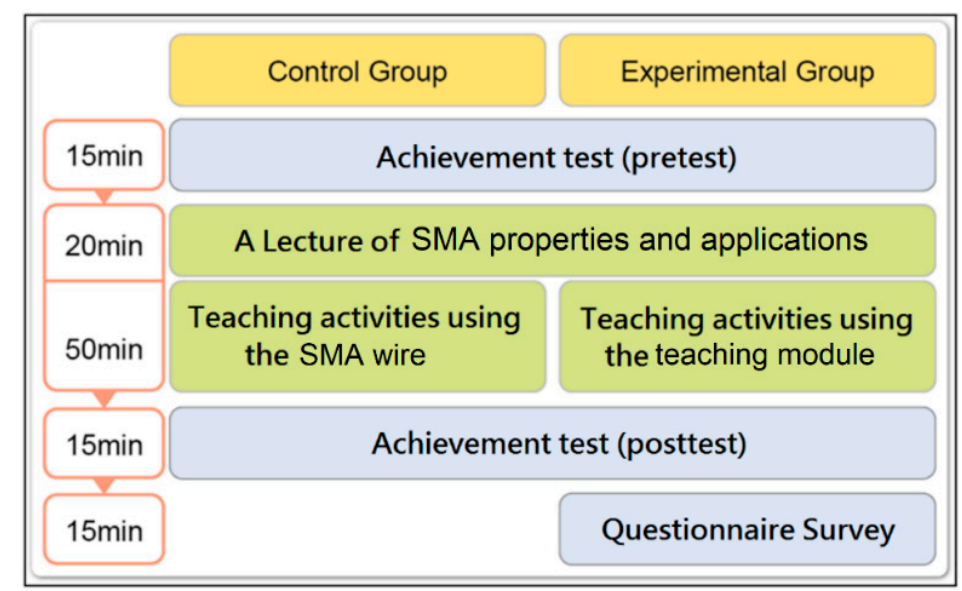

Figure 16. Flowchart of the teaching experiment.

Table 1. Variables of the teaching experiment.

\begin{tabular}{ccc}
\hline \multirow{2}{*}{ Independent Variables } & Control Group & Conducting the Real Experiment \\
\cline { 2 - 3 } & Experimental Group & Conducting the Virtual Experiment \\
\hline Covariance & Pretest of the achievement test \\
\hline Dependent variable & Posttest of the achievement test \\
\hline Control variables & Learning contents, teacher and teaching time \\
\hline
\end{tabular}

\subsection{Research Tools}

In this study, the following research tools were used: the SMA wire, the teaching module, the achievement test, and the questionnaire used by the experimental group:

- The teaching module

The teaching module can be executed on mobile or head-mounted devices. Its learning contents include the material properties and applications of the SMA. The application software was used by the experimental group and it was installed on the tablet PC (Figure 17).
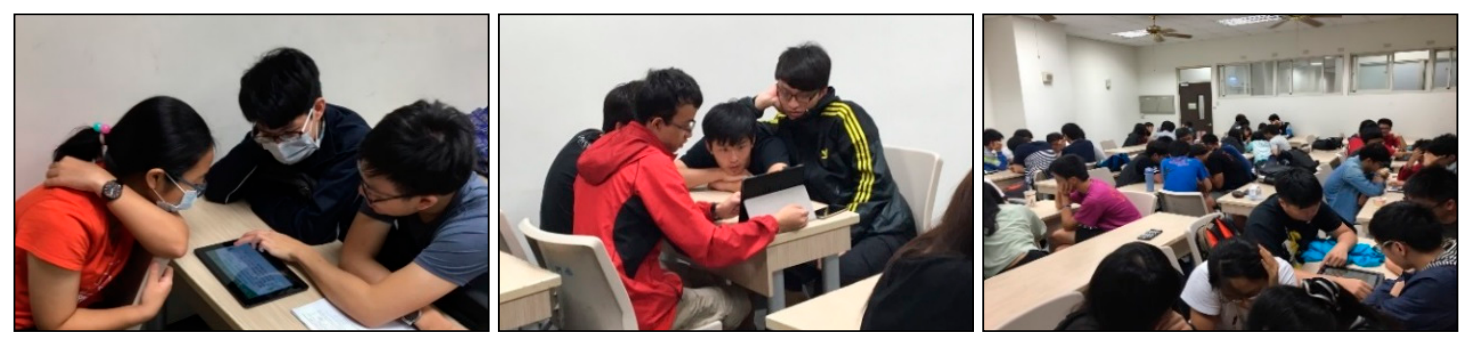

Figure 17. Teaching module used by the experimental group. 
- $\quad$ SMA wire

The SMA wire was used by the control group to conduct the real shaping experiment (Figure 18). After creating different shapes with the SMA wire, the students put their works into the oven where the temperature was set to increase $10{ }^{\circ} \mathrm{C}$ per minute up to $500{ }^{\circ} \mathrm{C}$. After cooling, the works were returned to students to check if they had shape memory effects.
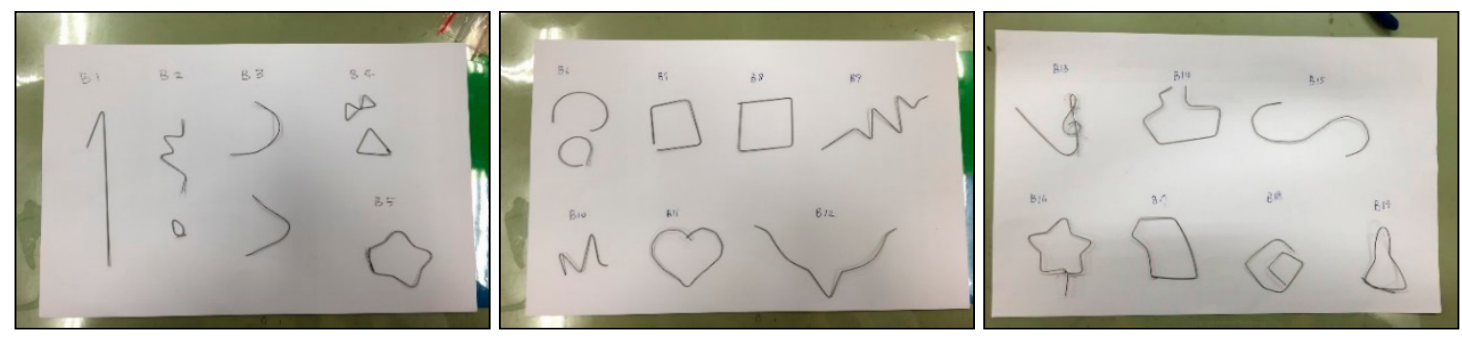

Figure 18. Different shapes of SMA wire folded by the control group.

- $\quad$ Achievement test

The achievement test was designed according to the SMA learning contents, including the manufacturing process, shape memory properties, principles and real-life applications. A number of 20 multiple-choice questions were designed and revised by two SMA experts and the science teacher (The test questions are listed in Appendix A).

- Questionnaire survey

The questionnaire is a system satisfaction survey containing 17 questions, which are divided into three categories (five questions on learning contents, five questions on user interface, and seven questions on operational experience). It was designed to investigate students' attitude after using the teaching module. When designing a new questionnaire for usability survey, it should be pilot tested and validated to make sure it is conducting the measurement reliably [34]. The questionnaire has been revised before taking the survey according to the suggestions of two SMA experts and the science teacher.

- Observation records

The experimental process has been observed and recorded to provide qualitative results for interpreting phenomena in terms of the meanings students brought to them to develop deep understandings on what they perceived as evidence for supporting the quantitative analysis.

\subsection{Comparison of Learning Achievement}

After the teaching experiment, an analysis of covariance (ANCOVA) is conducted to compare the learning effectiveness between the two groups to see whether a significant difference exists due to different teaching methods. This study uses the software IBM SPSS Statistics (2018, IBM Corp., Armonk, NY, USA) to analyze the results of the achievement tests. The average scores of the pretest and the posttest for the control group are 55.22 and 60.29, respectively; the average scores of the pretest and the posttest for the experimental group are 54.90 and 67.69, respectively. As we show in Table 2, the experimental group made a progress of 12.79 , which is higher than the progress made by the control group (5.07). 
Table 2. Descriptive statistics of achievement test.

\begin{tabular}{cccccc}
\hline & $\begin{array}{c}\text { Achievement } \\
\text { Test }\end{array}$ & $\begin{array}{c}\text { Number of } \\
\text { Students }\end{array}$ & $\begin{array}{c}\text { Average } \\
\text { Score }\end{array}$ & $\begin{array}{c}\text { Standard } \\
\text { Error }\end{array}$ & $\begin{array}{c}\text { Standard } \\
\text { Deviation }\end{array}$ \\
\hline \multirow{2}{*}{ Control group } & Pretest & 70 & 55.22 & 1.58 & 13.23 \\
\cline { 2 - 6 } & Posttest & 70 & 60.29 & 1.54 & 12.85 \\
\hline \multirow{2}{*}{$\begin{array}{c}\text { Experimental } \\
\text { Group }\end{array}$} & Pretest & 52 & 54.90 & 1.59 & 11.48 \\
\cline { 2 - 6 } & Posttest & 52 & 67.69 & 2.10 & 15.13 \\
\hline
\end{tabular}

The Levene's test is used in this study to compare if there is a significant difference in the pretest results of SMA knowledge between the two groups. The results, $\mathrm{f}=1.93$ and $p=0.17>0.05$, show that no significant difference exists, so the SMA knowledge of the two groups before the teaching activities was approximately equivalent. This study performs a statistical analysis on the pretest and posttest results for both groups by using a paired sample t-test to find out if there is a significant progress made by the students using different learning tools. The results for the control group show that $\mathrm{t}=2.98$ and $p=0.004<0.01$, revealing the real SMA experiment can enhance the learning achievement effectively. The results for the experiment group show that $\mathrm{t}=6.55$ and $p<0.001$, revealing the virtual experiment can also enhance their learning achievement effectively (Table 3).

Table 3. Statistical results of the paired sample t-test.

\begin{tabular}{ccccccc}
\hline & $\begin{array}{c}\text { Mean of } \\
\text { Progress }\end{array}$ & $\begin{array}{c}\text { Standard } \\
\text { Deviation }\end{array}$ & $\begin{array}{c}\text { Standard } \\
\text { Error }\end{array}$ & $\mathbf{t}$ & $\begin{array}{c}\text { Degree of } \\
\text { Freedom }\end{array}$ & Significance $(p)$ \\
\hline Control group & 5.07 & 14.26 & 1.70 & 2.98 & 69 & $p=0.004^{*}$ \\
Experimental group & 12.79 & 14.09 & 1.95 & 6.55 & 51 & $p<0.001^{* *}$ \\
\hline \multicolumn{7}{c}{$p<0.01^{*}, p<0.001^{* *}}$.
\end{tabular}

When performing the ANCOVA, it is required to satisfy the homogeneity of variance as well as the homogeneity of within-group regression coefficients.

- Homogeneity of variance

The Levene's test is used in this study to confirm the homogeneity of variance between the control group and the experimental group. The Levene's test results show that the variance has not achieved the significant standard ( $\mathrm{f}=0.7$ and $p=0.4>0.05$ ) and therefore the assumption for the homogeneity of variance is satisfied.

- Homogeneity of within-group regression coefficients

For both groups, the homogeneity of within-group regression coefficients must be met before performing the ANCOVA. Similarly, the test results have not achieved the significant standard $(\mathrm{f}=1.37$ and $p=0.24>0.05$ ). Consequently, the dependent variable, as well as the covariance, are not affected by the independent variable and thus the assumption is satisfied.

An ANCOVA is used in the teaching experiment to compare the learning achievements between the experimental group and the control group. It is done by excluding the effect of dependent variable and covariance. The ANCOVA results show that the impact of the teaching method (independent variable) has affected the learning achievement (Table 4). A significant difference exists between the experimental group and the control group $(p=0.001)$. Since the learning achievement of the former is higher than that of the latter, it is inferred that learning achievements of students on the SMA knowledge can be improved more effectively by the virtual experiment than the real experiment. 
Table 4. ANCOVA results of students' learning achievement.

\begin{tabular}{cccccc}
\hline Source & Type III SS & Degree of Freedom & Mean Square & $\mathbf{f}$ & $\boldsymbol{p}$ \\
\hline Group & 1701.78 & 1 & 1701.78 & 10.72 & 0.001 \\
Error & 188891.81 & 119 & 158.76 & & \\
\hline
\end{tabular}

\subsection{Questionnaire Results}

The questionnaire results by the experimental group are derived by a statistical analysis to understand the attitudes of students after using the teaching module. For every question, the average score, as well as the number and percentage of each selected item, are calculated and shown in Appendix B. The questionnaire adopts a five-point Likert scale [35] (strongly agree: 5 points; agree: 4 points; neutral: 3 points; disagree: 2 points; strongly disagree: 1 point) to measure students' attitudes after using the teaching module. The reliability analysis is performed using the statistical software SPSS and the Cronbach's $\alpha=0.95$, showing a high standard of reliability.

- $\quad$ Learning contents

Most students thought the contents of the teaching module is easy to understand and enables them to learn the properties and applications of the SMA. They agreed that the teaching module could be used to learn the related knowledge and basic concepts of the SMA and it enabled them to understand the SMA's crystal structure may change with the temperature. The questionnaire results show that most students gave positive feedback on the learning contents. The average scores ranges from 4.27 to 4.40 , and the overall average score in this category is 4.33 .

- Interface design

Most students considered that the operation of the teaching module is easy and the simulation of the SMA properties and applications is close to the real situation. They thought the teaching module provides a friendly user interface as well as proper font sizes and clear images. However, the score for the operational speed is comparatively lower because the tablet PC needs more computation time in processing the $3 \mathrm{D}$ interaction but its $\mathrm{CPU}$ is not very powerful. Basically, the questionnaire results show that students were satisfied with the interface design. The average scores ranges from 3.63 to 4.37 , and the overall average score in this category is 4.12 .

- Operational experience

Most students could actively complete the learning activities and the online test by following system instructions. They felt that the teaching module could help them understand the SMA's properties and the shaping process, and they could also understand that the crystal structure of SMA may change with temperature. Students thought the teaching module could increase their learning interest and they would like to use it for learning the related knowledge and basic concepts of the SMA. The questionnaire results show that students were satisfied with their learning experience after using the teaching module. The average scores ranges from 3.94 to 4.25 , and the overall average score in this category is 4.1 .

\subsection{Observation Records}

The teaching experiment was conducted in the class of a materials science course at a university in Northern Taiwan. The students in both groups took the pretest before the lecture of teaching the SMA properties and applications. Then, the control group used the SMA wire while the experimental group used the teaching module for conducting the SMA shaping experiment, respectively. Due to the limited number of tablet PCs, three to four students in the experimental group shared a tablet PC in the teaching experiment. The instructor explained the operational procedure and then let the students 
conduct the learning activities. Since the SMA wire is expensive, three to four students in the control group shared a piece of SMA wire when conducting the shaping experiment. There were five teaching assistants on site to help with the teaching activities and answer questions.

During the teaching activity, students in the experimental group were curious about the virtual experiment in the teaching module and they were focused on learning the SMA knowledge. Most students had the ability to operate tablet PCs while using the teaching module and they discussed the learning contents with the group members actively. They considered the teaching module useful in learning the SMA properties and applications because it was easy to operate and could save a lot of time without incurring any danger or environmental pollution.

For the control group, the teaching assistants first demonstrated the shaping process of SMA and then provided students with a piece of SMA wire. The students had to be careful about the strength used when designing their works with the SMA wire because it was not any easy task. The works of different shapes created by students during the class had no shape memory effect yet, so the teaching assistants had to put them in the oven for the shaping process, which took about five hours. To save time, the science teacher prepared some SMA wire samples with shape memory for the students to continue the deformation and restoration processes. The students stretched and twisted the wire samples and they were surprised to see the immediate restoration to the original shapes when the SMA wire was put into hot water.

\section{Conclusions}

In this study, a teaching module is developed using VR technology and the research results of SMA products as the learning contents for learning the SMA properties, shaping and restoration processes, and real-life applications in an immersive and interactive way. It is helpful in enhancing students' understanding of the SMA's material properties and applications. A teaching experiment has been performed for investigating students' learning achievements and attitudes after using the teaching module. The experimental results reveal that:

(1) The teaching module is effective in improving the learning achievement.

Both groups made significant improvement after the teaching activities, indicating the shaping experiment using real SMA wire as well as the teaching module are both effective for improving the learning achievement. However, the ANCOVA results show that the learning effectiveness of the teaching module is significantly higher than that of the real shaping experiment.

(2) The students held positive attitudes towards the teaching module.

The questionnaire results show that students were mostly satisfied with the teaching module and they held positive attitudes towards the learning contents, interface design and operational experience. They considered the teaching module easy to operate, useful in increasing their learning interest, and effective in helping them understand the properties and applications of SMAs.

(3) The teaching module can save the cost and time of conducting real experiments.

Using the teaching module, there is no need to use the TEM to observe the SMA's crystal structures. Additionally, a high-temperature oven up to $500{ }^{\circ} \mathrm{C}$ is required in the shaping experiment and it takes more than $5 \mathrm{~h}$ for the shaping process to complete. Therefore, the teaching module is a useful tool in learning the basic concepts and applications of SMAs for educational purposes.

Author Contributions: Formal analysis; C.-J.C.; investigation: C.-M.L.; methodology: C.-Y.L.; resources: Y.-J.L.; writing-review and editing: W.T.

Funding: This research was funded by the Ministry of Science and Technology (MOST), Taiwan under the grant number 105-2514-S-007-004.

Conflicts of Interest: The authors declare no competing interests regarding the publication of this paper. 


\section{Appendix A Achievement Test of the Shape Memory Alloys}

1. Which of the following descriptions about the SMA is correct? (A) The SMA is an alloy that can always have shape memory. (B) The SMA is an interstitial alloy. (C) The SMA is a substitutional alloy. (D) The SMA has low production costs and simple manufacturing processes.

2. Which of the following is the most commonly used SMA? (A) In-Tl (B) Cu-Zn (C) Cu-Al-Ni (D) Ni-Ti

3. Which of the following is not a shape memory effect of the SMA? (A) One-way shape memory effect (B) Two-way shape memory effect (C) All-round shape memory effect (D) Reverse shape memory effect

4. What is the operating principle of the SMA motor after the SMA spring is deformed by electric heating? (A) A tensile force is generated. (B) Pressure is generated. (C) A repulsive force is generated. (D) Elasticity is generated.

5. Which of the following is important during the initial smelting of the SMA? (A) The atomic ratio of the alloy will affect whether it needs to be smelted in a vacuum. (B) The atomic composition of the alloy will affect whether it needs to be smelted in a vacuum. (C) The atomic ratio of the alloy will affect the speed and temperature of the smelting. (D) The atomic composition of the alloy will affect the speed and temperature of the smelting.

6. The medical applications of the SMA for the treatment of patients such as the bone lamellae use the pressure generated by the SMA to fix broken bones for healing faster. Which of the following applications uses the same principle? (A) Dental braces (B) Vascular stents (C) Automatic fire alarms (D) Temperature control switches

7. What is the crystal structure of the shape memory alloy in the austenite phase?

(A)

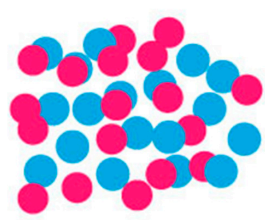

(B)

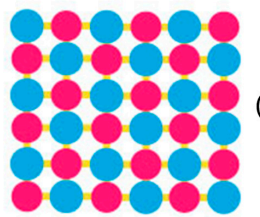

(C)

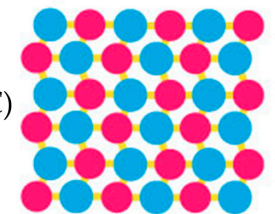

(D)

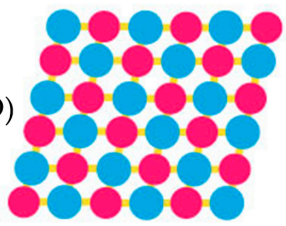

8. What is the crystal structure of the SMA after it is deformed by an external force?

(A)



(B)

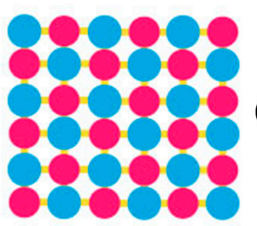

(C)

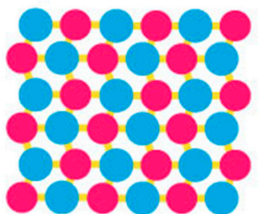

(D)

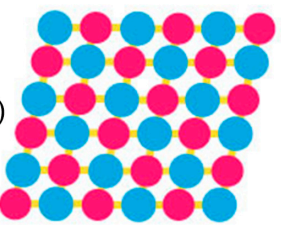

9. What is the crystal structure of the SMA after it is heated above the shaping temperature?

(A)

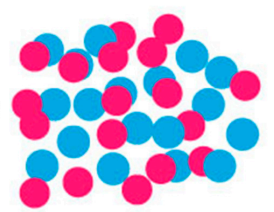

(B)

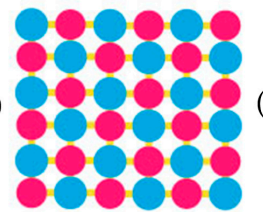

(C)

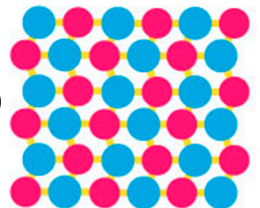

(D)

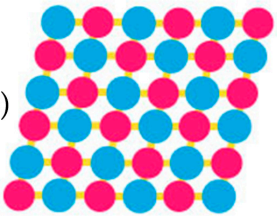

10. What is the order of crystal structure change after the SMA is deformed by an external force at room temperature, then restores its original shape after heating, and finally cools down to room temperature? (A)Austenite $\rightarrow$ Martensite $\rightarrow$ Martensite (B) Martensite $\rightarrow$ Martensite $\rightarrow$ Austenite (C) Austenite $\rightarrow$ Austenite $\rightarrow$ Martensite (D) Martensite $\rightarrow$ Austenite $\rightarrow$ Martensite

11. What is the correct order of the SMA's manufacturing process? (A) bedcaf (B) bacfed (C) bfceda (D) bcefda 


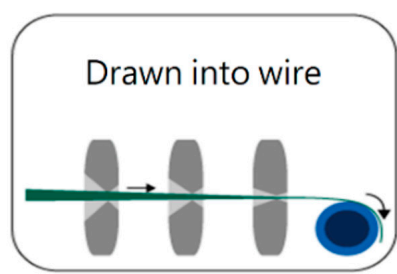

(a)

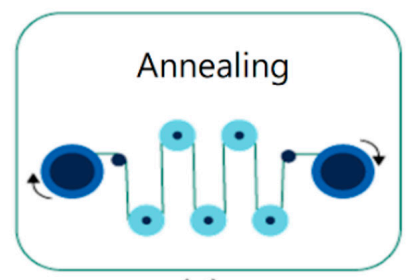

(d)

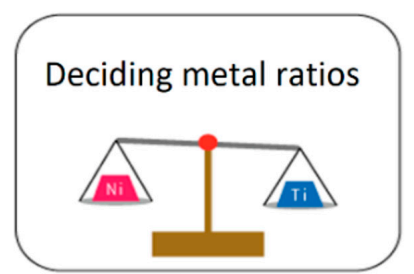

(b)

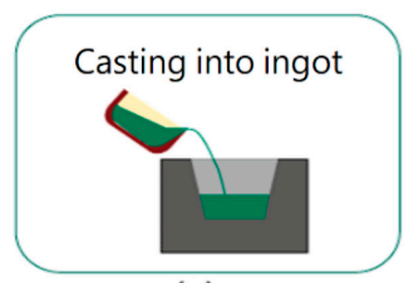

(e)

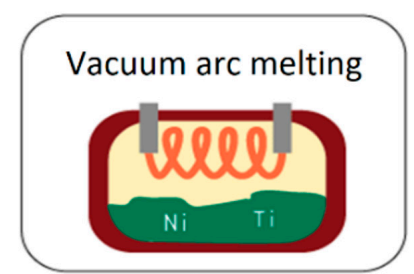

(c)

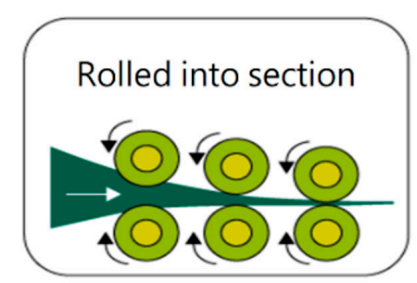

(f)

12. What is the most important factor affecting the transition temperature of an SMA during its manufacturing process? (A) Materials used in the SMA (B) Alloy smelting equipment (C) Composition ratio of the SMA (D) Casting shape of the SMA

13. Shape memory alloys can be used in many products. Which of the following has already been widely used? (A) Eyeglass frame (B) Car bearing shaft (C) Camera casing (D) Wind turbine

14. What is the industrial shaping process of the SMA? (A) High Temperature $\rightarrow$ Shaping $\rightarrow$ Cooling $\rightarrow$ Formation $\quad$ (B) $\quad$ Cooling $\rightarrow$ Shaping $\rightarrow$ High Temperature $\rightarrow$ Formation $\quad$ (C) Shaping $\rightarrow$ Cooling $\rightarrow$ High Temperature $\rightarrow$ Formation (D) Shaping $\rightarrow$ High Temperature $\rightarrow$ Cooling $\rightarrow$ Formation

15. The Ni-Ti SMA has unique shape memory recovery characteristics, superelasticity, and fatigue resistance. Which of the following characteristics is further required for its medical applications? (A) Heat transferability (B) Biodegradability (C) Biocompatibility (D) Conductivity

16. What can we find out in the shaping process of the SMA? (A) The SMA has a shape memory effect after cold working. (B) The SMA has a certain resistance at high temperatures. (C) During the cooling process, we can still change the shape memory of the SMA. (D) The crystal structure of the SMA does not change during the cooling process.

17. How can the SMA vascular stent help treat blood vessel diseases? (A) Clearing cancer cells (B) Opening the blocked blood vessel (C) Preventing blood clotting from flowing to the heart (D) Reinforcing fibrotic vessels

18. During the shaping process of the Ni-Ti SMA, what is the temperature and time interval required to achieve a better shape memory effect? (A) $400{ }^{\circ} \mathrm{C} / 4 \mathrm{~h}$ (B) $500{ }^{\circ} \mathrm{C} / 5 \mathrm{~h}$ (C) $600{ }^{\circ} \mathrm{C} / 6 \mathrm{~h}$ (D) 700 ${ }^{\circ} \mathrm{C} / 7 \mathrm{~h}$

19. During the shaping process, a heavy iron block is placed on top of the SMA wire after it is bent into a star shape. How will the shape of SMA wire change if the shaping process is conducted without the iron block? (A) It remains unchanged. (B) The star will concentrically enlarge. (C) The star will concentrically shrink. (D) The star will warp.

20. In the manufacturing process of an SMA, many misalignments may occur to result in hardening during the cold working step such as rolling. Therefore, annealing must be performed to eliminate hardening for the SMA to have better shape memory properties. The SMA is widely used in biomedical applications, such as: vascular stents and dental braces. When the SMA is in the martensite phase and plastically deformed within the limited extent, it can be transformed into the austenite phase by heating to the transition temperature, where the SMA will restore its original shape. What is the main mechanism of stress deformation in the martensite phase? (A) Grain boundary sliding (B) Sliding of coherent twin boundaries (C) Slip displacement (D) Diffusion 


\section{Appendix B}

Table A1. Questionnaire Results by Students after Using the Teaching Module.

\begin{tabular}{|c|c|c|c|c|c|c|c|c|}
\hline \multirow[b]{2}{*}{ 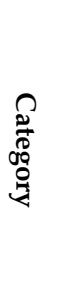 } & \multirow[b]{2}{*}{ Questions } & \multicolumn{5}{|c|}{ Student Number and Percentage } & \multirow[b]{2}{*}{ 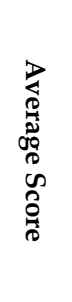 } & \multirow{2}{*}{ 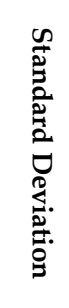 } \\
\hline & & 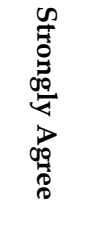 & 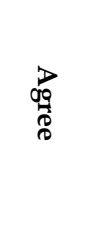 & 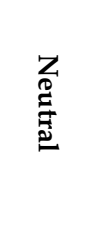 & 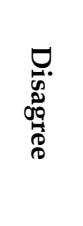 & 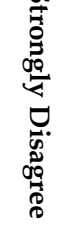 & & \\
\hline \multirow{10}{*}{ 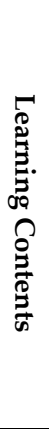 } & \multirow{2}{*}{$\begin{array}{l}\text { 1. The textual descriptions in the teaching } \\
\text { module are easy to understand. }\end{array}$} & 22 & 25 & 5 & 0 & 0 & \multirow{2}{*}{4.33} & \multirow{2}{*}{0.65} \\
\hline & & $42.3 \%$ & $48.1 \%$ & $9.6 \%$ & $0 \%$ & $0 \%$ & & \\
\hline & \multirow{2}{*}{$\begin{array}{l}\text { 2. The contents of the teaching module enable } \\
\text { me to understand the principles of SMAs. }\end{array}$} & 25 & 23 & 4 & 0 & 0 & \multirow{2}{*}{4.40} & \multirow{2}{*}{0.63} \\
\hline & & $48.1 \%$ & $44.2 \%$ & $7.7 \%$ & $0 \%$ & $0 \%$ & & \\
\hline & \multirow{2}{*}{$\begin{array}{l}\text { 3. The teaching module makes me become } \\
\text { familiar with the applications of SMAs. }\end{array}$} & 21 & 24 & 7 & 0 & 0 & \multirow{2}{*}{4.27} & \multirow{2}{*}{0.69} \\
\hline & & $40.4 \%$ & $46.1 \%$ & $13.5 \%$ & $0 \%$ & $0 \%$ & & \\
\hline & \multirow{2}{*}{$\begin{array}{l}\text { 4. The teaching module enables me to know } \\
\text { that the crystal structure of an SMA may } \\
\text { change with temperatures. }\end{array}$} & 23 & 25 & 4 & 0 & 0 & \multirow[b]{2}{*}{4.37} & \multirow[b]{2}{*}{0.63} \\
\hline & & $44.2 \%$ & $48.1 \%$ & $7.7 \%$ & $0 \%$ & $0 \%$ & & \\
\hline & \multirow{2}{*}{$\begin{array}{l}\text { 5. The teaching module can be used to learn } \\
\text { the related knowledge of SMAs. }\end{array}$} & 20 & 27 & 4 & 1 & 0 & \multirow{2}{*}{4.27} & \multirow{2}{*}{0.69} \\
\hline & & $38.5 \%$ & $51.9 \%$ & $7.7 \%$ & $1.9 \%$ & $0 \%$ & & \\
\hline \multirow{10}{*}{ 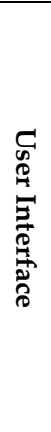 } & \multirow{2}{*}{$\begin{array}{l}\text { 6. The operation of the teaching module is } \\
\text { easy. }\end{array}$} & 25 & 23 & 2 & 2 & 0 & \multirow{2}{*}{4.37} & \multirow{2}{*}{0.74} \\
\hline & & $48.1 \%$ & $44.2 \%$ & $3.9 \%$ & $3.9 \%$ & $0 \%$ & & \\
\hline & \multirow{2}{*}{$\begin{array}{l}\text { 7. The font sizes of the teaching module are } \\
\text { proper and its images are clear. }\end{array}$} & 23 & 21 & 7 & 1 & 0 & \multirow{2}{*}{4.27} & 077 \\
\hline & & $44.2 \%$ & $40.4 \%$ & $13.5 \%$ & $1.9 \%$ & $0 \%$ & & 0.11 \\
\hline & 8. The user interface of the teaching module is & 21 & 24 & 6 & 1 & 0 & & \\
\hline & friendly. & $40.4 \%$ & $46.2 \%$ & $11.5 \%$ & $1.9 \%$ & $0 \%$ & 4.25 & 0.74 \\
\hline & 9. The simulation of the SMA shaping process & 19 & 18 & 15 & 0 & 0 & & \\
\hline & $\begin{array}{l}\text { and applications are close to the real } \\
\text { situation. }\end{array}$ & $36.5 \%$ & $34.6 \%$ & $28.9 \%$ & $0 \%$ & $0 \%$ & 4.08 & 0.81 \\
\hline & 10. The execution speed of the teaching module & 12 & 15 & 20 & 4 & 1 & 363 & 000 \\
\hline & is satisfactory. & $23.1 \%$ & $28.9 \%$ & $38.5 \%$ & $7.7 \%$ & $1.9 \%$ & 3.63 & 0.99 \\
\hline & 11. When using the teaching module, I can & 13 & 26 & 12 & 1 & 0 & & \\
\hline & $\begin{array}{l}\text { actively complete the learning activities by } \\
\text { following the instructions. }\end{array}$ & $25 \%$ & $50 \%$ & $23.1 \%$ & $1.9 \%$ & $0 \%$ & 3.98 & 0.75 \\
\hline & 12. The teaching module helps me understand & 18 & 27 & 7 & 0 & 0 & 4.21 & 0.67 \\
\hline & the principles of SMAs. & $34.6 \%$ & $51.9 \%$ & $13.5 \%$ & $0 \%$ & $0 \%$ & 4.21 & 0.67 \\
\hline 胥 & 13. The teaching module increases my interest & 16 & 24 & 12 & 0 & 0 & 408 & 074 \\
\hline 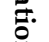 & in learning the related knowledge of SMAs. & $30.8 \%$ & $46.2 \%$ & $23.1 \%$ & $0 \%$ & $0 \%$ & 4.08 & 0.14 \\
\hline$\tilde{D}$ & 14. The teaching module helps me understand & 19 & 28 & 5 & 0 & 0 & 427 & 063 \\
\hline$\underset{x}{x}$ & the shaping process of SMAs. & $36.5 \%$ & $53.9 \%$ & $9.6 \%$ & $0 \%$ & $0 \%$ & & \\
\hline D & 15. After using the teaching module, I would & 15 & 22 & 14 & 1 & 0 & 398 & 080 \\
\hline ?. & like to learn about the knowledge of SMAs. & $28.9 \%$ & $42.3 \%$ & $26.9 \%$ & $1.9 \%$ & $0 \%$ & & \\
\hline $\overrightarrow{0}$ & 16. I understand that the crystal structure of the & 20 & 25 & 7 & 0 & 0 & & \\
\hline & $\begin{array}{l}\text { SMA may change with temperatures after } \\
\text { using the teaching module. }\end{array}$ & $38.5 \%$ & $48.1 \%$ & $13.5 \%$ & $0 \%$ & $0 \%$ & 4.25 & 0.68 \\
\hline & $\begin{array}{l}\text { 17. I like to use the teaching module to learn the } \\
\text { basic concepts of SMAs. }\end{array}$ & 11 & 30 & 9 & 1 & 1 & 3.94 & 0.80 \\
\hline
\end{tabular}

\section{References}

1. Chang, L.C.; Read, T.A. Plastic deformation and diffusionless phase changes in metals-The gold-cadmium beta phase. Trans. AIME 1951, 189, 47-52. [CrossRef]

2. Buehler, W.J.; Gilfrich, J.V.; Wiley, R.C. Effect of low temperature phase changes on the mechanical properties of alloys near composition TiNi. J. Appl. Phys. 1963, 34, 1475-1477. [CrossRef] 
3. Krishnan, R.V.; Brown, L.C. Pseudoelasticity and the strain-memory effect in an Ag-45 At. Pct Cd alloy. Metall. Trans. 1973, 4, 423-429. [CrossRef]

4. Si, N.C.; Sun, K.Q.; Sun, S.C.; Liu, H.X. Damping performance of Cu-Zn-Al shape memory alloys in engineering structures. J. Cent. South Univ. T. 2004, 11, 246-251. [CrossRef]

5. Lojen, G.; Anzel, I.; Kneißl, A.; Krizman, A.; Unterweger, E.; Kosec, B.; Bizjak, M. Microstructure of rapid solidified Cu-Al-Ni shape memory alloy ribbons. J. Mater. Process. Technol. 2005, 162-163, 220-229. [CrossRef]

6. Mabe, J.H.; Calkins, F.T.; Alkislar, M.B. Variable Area Jet Nozzle Using Shape Memory Alloy Actuators in an Antagonistic Design. In Proceedings of the Industrial and Commercial Applications of Smart Structures Technologies 2008, San Diego, CA, USA, 10-11 March 2008.

7. Lagoudas, D.C.; Hartl, D.J. Aerospace applications of shape memory alloys. J. Aerospace Eng. 2007, 221, 535-552.

8. Song, G.; Ma, N.; Li, H.N. Applications of shape memory alloys in civil structures. Eng. Struct. 2006, 28, 1266-1274. [CrossRef]

9. Machado, L.G.; Savi, M.A. Medical applications of shape memory alloys. Braz. J. Med. Biol. Res. 2003, 36, 683-691. [CrossRef]

10. Alaneme, K.K.; Okotete, E.A. Reconciling viability and cost-effective shape memory alloy options-A review of copper and iron based shape memory metallic systems. Eng. Sci. Technol. 2016, 19, 1582-1592. [CrossRef]

11. Markopoulos, A.P.; Pressas, I.S.; Manolakos, D.E. A review on the machining of nickel-titanium shape memory alloys. Rev. Adv. Mater. Sci. 2015, 42, 28-35.

12. Neogy, S.; Savalia, R.T.; Tewari, R.; Srivastava, D.; Dey, G.K. Transmission electron microscopy of nanomaterials. Indian J. Pure Appl. Phys. 2006, 44, 119-124.

13. Kim, G. Designing Virtual Reality Systems: The Structured Approach; Springer: Heidelberg, Germany, 2005.

14. Tarng, W.; Tsai, C.F.; Lin, C.M.; Lee, C.Y.; Liou, H.H. Development of an educational virtual transmission electron microscope laboratory. Virtual Reality 2015, 19, 33-44. [CrossRef]

15. Tarng, W.; Ou, K.L.; Yu, C.S.; Liou, F.L.; Liou, H.H. Development of a virtual butterfly ecological system based on augmented reality and mobile learning technologies. Virtual Reality 2015, 19, 253-266. [CrossRef]

16. Hou, L.; Chi, H.L.; Tarng, W.; Chai, J.; Panuwatwanich, K.; Wang, X. A framework of innovative learning for skill development in complex operational tasks. Automat. Constr. 2017, 83, 29-40. [CrossRef]

17. Rizman Herga, N.; Čagran, B.; Dinevski, D. Virtual laboratory in the role of dynamic visualisation for better understanding of chemistry in primary school. Eurasia J. Math. 2016, 12, 593-608.

18. Kilani, M.; Torabi, K.; Mao, G. Application of virtual laboratories and molecular simulations in teaching nanoengineering to undergraduate students. Comput. Appl. Eng. Educ. 2018, 26, 1527-1538. [CrossRef]

19. Uribe, M.R.; Magana, A.J.; Bakh, J.H.; Shakouri, A. Computational simulations as virtual laboratories for online engineering education: A case study in the field of thermoelectricity. Comput. Appl. Eng. Educ. 2016, 24, 428-442. [CrossRef]

20. Schott, C.; Marshall, S. Virtual reality and situated experiential education: A conceptualization and exploratory trial. J. Comput. Assist. Learn. 2018, 34, 843-852. [CrossRef]

21. Parong, J.; Mayer, R.E. Learning science in immersive virtual reality. J. Educ. Psychol. 2018, 110, 785-797. [CrossRef]

22. Christopoulos, A.; Conrad, M.; Shukla, M. Increasing student engagement through virtual interactions: How? Virtual Reality 2018, 22, 353-369. [CrossRef]

23. Tarng, W.; Hsie, C.C.; Lin, C.M.; Lee, C.Y. Development and application of a virtual laboratory for synthesizing and analyzing nanogold particles. J. Comput. 2017, 12, 270-283.

24. de Jong, T.; Marcia, C.; Linn, M.C.; Zacharia, Z.C. Physical and virtual laboratories in science and engineering education. Science 2013, 340, 305-308. [CrossRef] [PubMed]

25. Wang, T.L.; Tseng, Y.K. The comparative effectiveness of physical, virtual, and virtual-physical manipulatives on third-grade students' science achievement and conceptual understanding of evaporation and condensation. Int. J. Sci. Math. Educ. 2018, 16, 203-219. [CrossRef]

26. Zhang, X.; Jiang, S.; de Pablos, P.O.; Lytras, M.D.; Sun, Y. How virtual reality affects perceived learning effectiveness: A task-technology fit perspective. Behav. Infor. Technol. 2017, 36, 548-556. [CrossRef]

27. Casperse, J.; Smeby, J.C.; Aamodt, P.O. Measuring learning outcomes. Eur. J. Educ. 2017, 52, 20-30. [CrossRef]

28. Lei, C.H.; Li, L.J.; Shu, Y.C.; Li, J.Y. Austenite-martensite interface in shape memory alloys. Appl. Phys. Lett. 2010, 96, 141910. [CrossRef] 
29. Spini, T.S.; Valarelli, F.P.; Cançado, R.H.; Freitas, K.M.S.; Villarinho, D.J. Transition temperature range of thermally activated nickel-titanium archwires. J. Appl. Oral Sci. 2014, 22, 109-117. [CrossRef]

30. Ryklina, E.P.; Prokoshkin, S.D.; Khmelevskaya, Y.I.; Shakhmina, A.A. One-way and two-way shape memory effect in thermomechanically treated TiNi-based alloys. Mater. Sci. Eng. A 2008, 481, 134-137. [CrossRef]

31. Jani, J.M.; Leary, M.; Subic, A. Shape Memory Alloys in Automotive Applications. Appl. Mech. Mater. 2014, 663, 248-253. [CrossRef]

32. Kapoor, D. Nitinol for medical applications: A brief introduction to the properties and processing of nickel titanium shape memory alloys and their use in stents. Johnson Matthey Technol. Rev. 2017, 61, 66-76. [CrossRef]

33. Andreasen, G.F.; Hilleman, T.B. An evaluation of 55 cobalt substituted Nitinol wire for use in orthodontics. J. Am. Dent. Assoc. 1971, 82, 1373-1375. [CrossRef] [PubMed]

34. Venkatesh, V.; Morris, M.G.; Davis, G.B.; Davis, F.D. User acceptance of information technology: Toward a unified view. MIS Quart. 2003, 27, 425-478. [CrossRef]

35. Allen, I.E.; Seaman, C.A. Likert scales and data analyses. Qual. Prog. 2007, 40, 64-65.

(C) 2019 by the authors. Licensee MDPI, Basel, Switzerland. This article is an open access article distributed under the terms and conditions of the Creative Commons Attribution (CC BY) license (http://creativecommons.org/licenses/by/4.0/). 